\title{
Análise da perda de terreos agrícolas na periferia de Lugo mediante regresións loxísticas e modelos de autómatas celulares
}

Recibido: 1 setembro 2015 / Aceptado: 8 marzo 2016

(C) IBADER- Universidade de Santiago de Compostela 2015

\begin{abstract}
Resumo As melloras tecnolóxicas da revolución industrial, xeraron un proceso de concentración da poboación nas cidades e de perda dos vínculos coas zonas rurais que as rodean. Estas dinámicas orixinaron un decaemento da agricultura local e unha perda de terreos agrícolas en favor de usos urbanos. Tendo en conta os retos que presentan o cambio climático, a escaseza de combustibles e o aumento da poboación urbana, xéranse unha serie de incertezas sobre soberanía e seguridade alimentarias ás que cómpre dar resposta mediante o fomento da agricultura periurbana. No presente traballo estudarase a evolución dos usos agrícolas da cidade de Lugo. Para iso analizáronse os cambios dos usos do solo cruzando mapas de usos de varios anos e utilizando regresións loxísticas. Finalmente xerouse un mapa de probabilidade de urbanización para o ano 2021 mediante un modelo de autómata celular que se cruzou cun mapa de aptitude agrícola para coñecer as zonas de alta aptitude agrícola con risco de seren urbanizadas. A metodoloxía empregada permitiu identificar factores condicionantes da perda de usos agrícolas e as zonas onde desenvolver políticas de planeamento que permitan preservar os mellores terreos agrícolas da periferia de Lugo.
\end{abstract}

Palabras clave agricultura periurbana, crecemento urbano, cambios de usos do solo, modelos espaciais.

Abstract Technology improvements during industrial revolution fostered a process of population concentration in cities and a loss of links with the rural areas that surround

Andrés Manuel García · Cristina Caamaño

Laboratorio do Territorio, Universidade de Santiago de

Compostela. Escola Politécnica Superior, Campus Universitario

s/n, 27002 Lugo.

Tel.: 0034982823292 .

E-mail: andresmanuel.garcia@usc.es them. These dynamics originated a decay of local agriculture and a loss of agriculture land in favour of urban land uses. Considering the challenges that climate change, oil scarcity and a growing urban population impose, a series of uncertainties are generated around food safety and sovereignty which should be tackled by fostering peri-urban agriculture. In the present work, agriculture land uses in the city of Lugo will be studied. For this, land use changes were analysed crossing land use maps of several years and using logistic regressions. Finally an urbanization probability map was generated for 2021, using a cellular automata model. This map was crossed with an agriculture suitability map to identify areas with high suitability which risk to be urbanized. The used methodology, allowed identifying drivers of agriculture land loss and the areas where to implement planning policies aimed at preserving best agriculture land in the periphery of Lugo.

Key words Peri-urban agriculture, urban grow, land use changes, spatial models.

\section{Introdución}

As melloras tecnolóxicas na produción, transporte e conservación de alimentos durante a revolución industrial, posibilitaron que a poboación crecente das cidades se puidese abastecer de alimentos baratos traídos de zonas distantes. A caída dos prezos que isto supuxo, fomentou o declive das zonas rurais próximas ás cidades. Como consecuencia, as áreas urbanas romperon o vínculo coa periferia rural que as abastecía de alimentos (Steel 2008). Esta ruptura viuse agravada pola perda de terreos arables debido ao crecemento urbano e pola absorción de man de obra agrícola por parte da industria, dando lugar a un proceso de marxinalización da actividade agrícola na periferia urbana (Pinto-Correia e Breman 2008).

En Galicia, este proceso viuse retrasado pola guerra civil española. Nos anos 60 , os plans de desenvolvemento concibidos para saír da posguerra, crearon polos industriais nas principais cidades galegas. As novas industrias atraeron 
man de obra das zonas agrícolas periurbanas e de zonas rurais máis distantes (Alonso e Lois 1997, Ferrás Sexto, 2011) fomentando un proceso de crecemento urbano. Por outro lado, as melloras socioeconómicas permitiron construír novas infraestruturas e incrementaron a adquisición de vehículos privados, mellorándose así a mobilidade. O crecemento urbano, a mellora na mobilidade e a dispersión característica dos asentamentos de poboación galegos facilitaron o espallamento das cidades a conta das zonas rurais circundantes (Otero Enríquez e Gómez Rodríguez, 2007, Precedo Ledo et al., 2008), polo que se incrementou a presión dos usos urbanos sobre os agrícolas. O proceso de marxinalización da agricultura debido á presión urbana e á drenaxe de man de obra polos sector servizos e industrial, viuse agravado pola competencia con zonas agrícolas máis industrializadas debido á entrada de España na Unión Europea e a apertura aos mercados internacionais de alimentos (López Iglesias, 2000). Malia este proceso, as periferias urbanas de Vigo, Santiago e Coruña aínda teñen bastante peso a nivel galego na produción de cultivos de alto valor engadido como froitas e hortalizas (Carreira Pérez e Carral Vilariño 2014).

As dinámicas anteriormente vistas xeran unha serie de riscos para a seguridade e soberanía alimentarias, xa que as áreas urbanas dependen cada vez máis dun mercado globalizado para abastecérense de alimentos e dos vaivéns do mesmo (Pollan, 2008). Isto é "se cabe" máis serio se se ten en conta que hoxe en día; o $52 \%$ da poboación mundial xa é urbana e espérase que para o 2050 esta porcentaxe sexa do $68 \%$ (UN-HABITAT, 2010). Polo tanto, a actividade agrícola periurbana, resulta clave para a sustentabilidade e seguridade alimentarias das cidades

A produción local de alimentos cobra maior importancia ante os retos que se presentan no futuro debido á escaseza de combustibles, o cambio climático e o incremento da poboación urbana. Por iso, é preciso dispoñer de ferramentas que axuden a entender os procesos de perda de usos do solo agrícola nas periferias urbanas e identificar aquelas zonas de maior aptitude agrícola con alto risco de cambio do uso do solo. Deste xeito, poderanse desenvolver políticas eficaces para poder protexer os usos agrícolas da expansión das cidades.

No presente traballo tomarase como referencia a cidade de Lugo e analizaranse os procesos de perda de usos agrícolas na súa periferia mediante métodos de regresión loxística. Posteriormente desenvolverase una metodoloxía para identificar as zonas de maior aptitude agrícola que corren maior risco de seren urbanizadas. Para elo empregarase un mapa de aptitude do solo para os usos agrícolas e un modelo de autómata celular para determinar probabilidades de urbanización.

Os autómatas celulares (AC) teñen sido amplamente utilizados para simular e analizar procesos de cambio de usos do solo, pois ofrecen a posibilidade de reproducir dinámicas espaciais complexas a partir de regras simples e fáciles de interpretar (Jenerette e Wu 2001). Existen numerosos autores que teñen utilizado estes modelos para estudar os procesos de perda de terreos agrícolas ou espazos naturais na periferia urbana: Li e Yeh (2000) utilizaron un modelo de AC para explorar patróns de crecemento urbano que preserven terreos de gran aptitude agrícola mediante a introdución de restricións ao crecemento nestas zonas. Os mesmos autores desenvolveron un modelo que xera probabilidades de urbanización nun escenario futuro de crecemento urbano ( $\mathrm{Li}$ e Yeh 2001). Deste xeito pódense identificar as zonas con maior risco de seren urbanizadas. Por outro lado, tamén se desenvolveron modelos de AC para o estudo das dinámicas de crecemento urbano e como estas poden ameazar valores naturais nas inmediacións das cidades (Jenerette e Wu 2001).

Os modelos empregados na bibliografía axudan a comprender as dinámicas urbanas ou ofrecen patróns de crecemento urbano alternativos que preservan un determinado uso do solo. Non obstante, a excepción do modelo de Li e Yeh (2001), non permiten identificar as zonas de maior aptitude agrícola con maior risco de seren urbanizadas. No caso do modelo de Li e Yeh (2001) a probabilidade de urbanización dunha determinada zona determínase en base ás porcentaxes de solo urbanizado da súa veciñanza. Isto xera estimacións pouco realistas xa que non se teñen en conta outro tipo de factores que inflúen no crecemento urbano. Co modelo que se empregará no presente traballo, non só se poden considerar un maior número de variables, senón que ao cruzar os mapas de probabilidade de urbanización resultantes con mapas de aptitude, será posible identificar os terreos con maior potencial para a agricultura que corren maior risco de seren edificados. A maiores, ao considerárense maior número de variables tamén se poderán estudar con maior detalle os procesos espaciais que condicionan a perda de terreos agrícolas.

Por outro lado, a nivel Galego existen estudos de cambios de usos do solo similares que explican os procesos de abandono da agricultura como o de Marey Pérez et al. (2006) que analiza as dinámicas de cambio do uso forestal mediante análises de conglomerados e outros métodos estatísticos, o de Corbelle Rico e Crecente Maseda (2014) que analiza as dinámicas de cambio de usos agrícolas en zonas rurais da Terra Chá mediante matrices de confusión ou o de Calvo Iglesias et al. (2006) que analizan mediante análise de conglomerados e matrices de confusión os cambios de uso e de estrutura da paisaxe nunha área do noroeste da provincia de Lugo. Incluso, existe un traballo de Corbelle Rico e Santé Riveira (2010) que estuda a perda de usos agrícolas na Terra Chá mediante metodoloxías similares á presentada neste estudo. Non obstante, no noso caso centrarémonos especificamente nas dinámicas de cambio de uso do solo na periferia urbana e utilizaranse modelos de simulación que permitan explorar as posibles consecuencias destas dinámicas.

Os resultados das análises feitas amosan que os usos urbanos de baixa densidade son os que máis solo agrícola están a consumir. Este tipo de crecemento repercute nunha maior necesidade de infraestruturas viarias que á súa vez consumen máis solo agrícola pois adóitase localizar na periferia urbana (Farr 2008). Por outro lado, os usos urbanos están a competir polos mellores terreos agrícolas e 
desprazan a actividade a zonas de menor aptitude como xa se ten demostrado nos traballos de Corbelle e Crecemte (2014). Grazas aos mapas obtidos mediante o cruce dos resultados do modelo cos mapas de aptitude agrícola, puidéronse identificar as áreas de alto valor agrícola que corren máis risco de desaparecer. Estas zonas están próximas aos dous polígonos industriais máis grandes da cidade. Con estes datos poderanse deseñar mellores políticas de planeamento que axuden a preservar estes terreos.

\section{Metodoloxía}

\section{Introduccíon do caso de estudo}

Lugo, xunto con Ourense, é unha das dúas cidades que prové servizos ao interior rural de Galicia. Como cabe esperar, o sector terciario é o de máis peso na súa economía ( $60 \%$ da poboación activa segundo datos do INE 2011) seguido do agrícola $(18 \%$ da poboación activa segundo INE 2011). Entre mediados dos noventa e o 2007, experimentouse un alto crecemento urbano na cidade, debido á construción do campus universitario e á burbulla da construción.

Lugo constitúe un caso de estudo interesante, debido á importancia da actividade agrícola nos núcleos periféricos e a presión á que esta se viu sometida nos útlimos anos por mor dos procesos de crecemento do casco urbano. Por este motivo elixiuse a cidade como caso de estudo.

Nun principio decidiuse tomar como zona de estudo o núcleo urbano de Lugo e as parroquias adxacentes; por seren estas as que sofren unha maior presión do crecemento do núcleo. Non obstante, debido á irregularidade na forma e tamaño das parroquias, nalgúns casos quedaban fóra zonas próximas ao casco urbano de Lugo e noutros incluíanse zonas que se atopaban demasiado lonxe. Por este motivo decidiuse coller unha banda dun quilómetro de ancho arredor do casco urbano como se indica no mapa de localización (figura 1). Tomouse esta distancia por ser a que abranguía a maior parte das zonas agrícolas das parroquias adxacentes ao casco urbano sen saírse do límite municipal de Lugo.

\section{Obtención de datos}

Co gallo de comprender mellor os procesos de cambio de uso do solo en Lugo, elaboráronse mapas de usos do solo da zona de estudo para os anos 1997, 2003 e 2009 (os coincidentes co período da burbulla da construción) a partir de fotointerpretación de ortofotos do Plan Nacional de Ortografía Aérea. A fointerpretación apoiouse no parcelario de catastro de 1995 en formato shape, en datos en formato shape de usos do solo do SIGPAC do 2009, en datos en formato shape de usos e coberturas do SITGA do 2004 e en datos en formato shape da Enquisa de Infraestruturas e Equipamentos Locais da provincia de Lugo do 2012.

Os usos do solo considerados na fotointerpretación foron os seguintes: residencial de baixa densidade (edificios de dúas ou menos plantas con xardín), residencial de alta densidade (edificios de máis de dúas plantas anexos e sen xardín), comercial (grandes superficies comerciais, mercados, hoteis e campings), industrial (naves industriais, talleres, gasolineiras, estabulacións grandes), institucional (edificios administrativos e de servizos), parques (parques, xardíns públicos e áreas recreativas), ermo (terreos sen

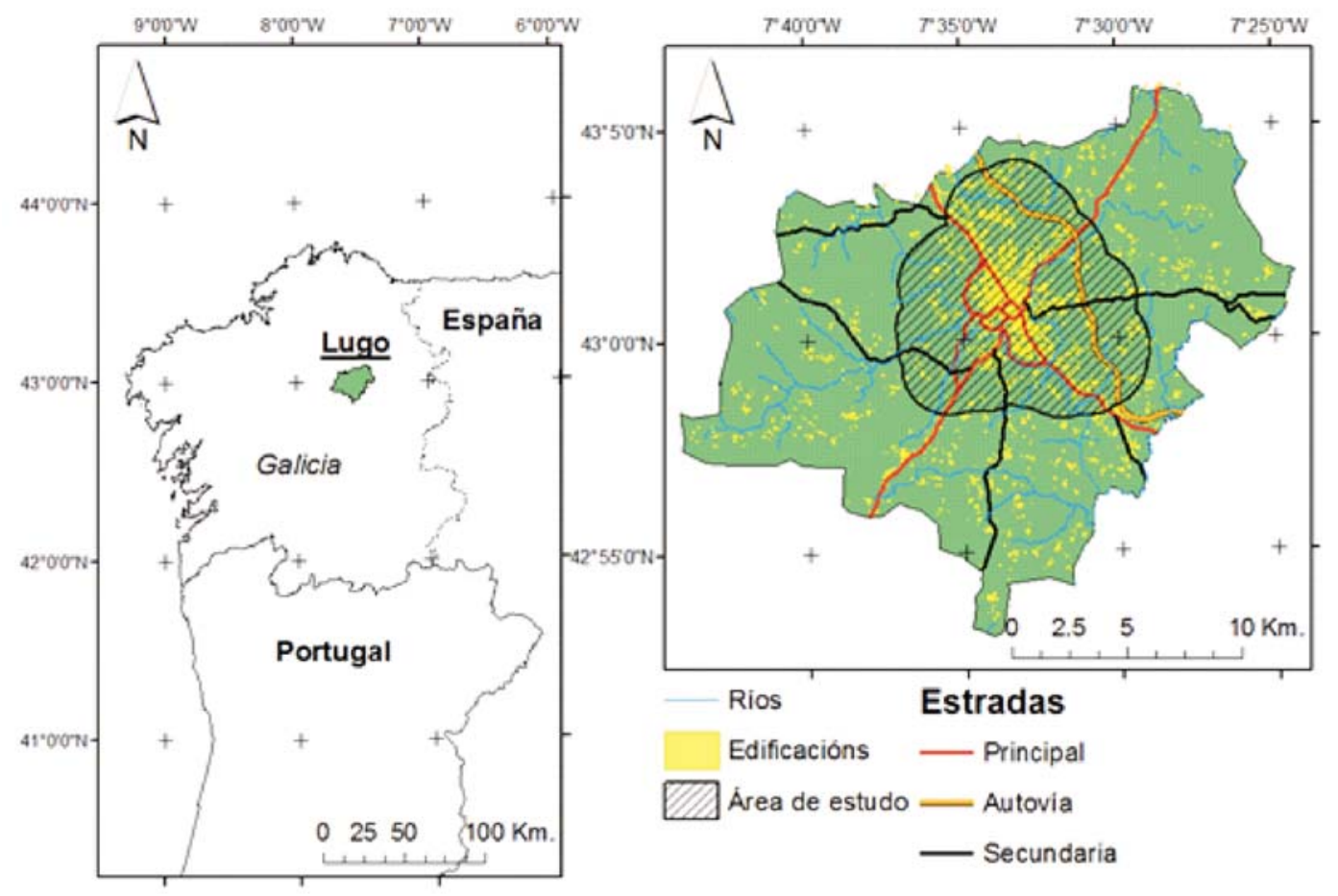

Figura 1.-Mapa de localización da área de estudo 
vexetación), agrícola (terreos con cultivos, arados, con invernadoiros ou árbores froiteiras), forestal (masas arboradas con máis do $20 \%$ da súa superficie cuberta polas copas), matogueira (matogueiras ou terreos con árbores cuxas copas non ocupen máis do $20 \%$ da superficie), masas de auga, vías de comunicación (estradas, camiños e vías do tren), excluído (Terreos que é difícil que cambien de uso; cemiterios, elementos patrimoniais, canteiras, penedos, vertedoiros clausurados).

Os mapas de usos obtidos para o ano 1997 e 2009 cruzáronse mediante unha matriz de confusión para estudar os cambios de usos do solo que se produciron neste intervalo de tempo. Unha vez analizados os cambios procedeuse a obter, a partir de datos espaciais, variables que puidesen explicar os cambios observados:

- Mapas de usos do solo obtidos a partir da fotointerpretación das ortofotos do PNOA: distancia a explotacións agropecuarias, distancia a uso comercial, distancia a uso industrial, distancia a uso institucional, distancia a parques e áreas recreativas, distancia a uso residencial de alta densidade, distancia a uso residencial de baixa densidade, distancia a usos agrícolas, distancia a uso forestal, distancia a masas de auga e distancia ao centro de Lugo.

- Parcelario do Catastro Español: Área de parcelas e índice de forma de parcelas (Ecuación 1.)

- Enquisa de Infraestruturas e Equipamentos Locais da Provincia de Lugo: distancia a autovías, distancia a estradas principais, distancia a estradas secundarias, distancia a estradas terciarias, distancia a camiños, distancia a rúas, distancia á vía do tren e distancia a nodos de comunicación (accesos á autovía)

- Modelo dixital do terreo de resolución 25x25m do centro de descargas do Instituto Xeográfico Nacional: Pendentes, orientación do terreo e altitude.

- Mapa de capacidade produtiva dos solos de Galicia (Díaz Fierros e Gil 1984) en formato shape.

$$
\text { Ec. 1: IF }=\frac{\text { Perimetro }}{4 \sqrt{\text { Área }}}
$$

Estas variables foron obtidas en formato ráster de $35 \times 35 \mathrm{~m}$ de tamaño de píxel. Escolleuse un tamaño de píxel que fose polo menos 1,5 veces maior que a superficie mediana das parcelas catastrais da zona de estudo. Deste xeito, o tamaño de píxel será representativo da superficie da maioría das parcelas.

Os datos anteriormente descritos foron procesados con ArcGIS 9.6 e IDRISI Andes para obter as variables a analizar. As análises de regresión loxística fixéronse co software estatístico $\mathrm{R}$ versión 3.2.0. Finalmente, as simulacións fixéronse co modelo SIMULA (García et. al 2013) desenvolto en Visual Basic. Net.

Análise dos cambios do usos do solo agrícola

Tras obtérense as variables procedeuse a analizar como inflúen nos cambios do uso do solo agrícola nos períodos 1997-2003 e 2003-2009. Antes de facer as análises estudouse a correlación entre as variables mediante o índice de Spearman. Considerouse que as variables que tiñan un índice de Spearman maior de 0.7 ou menor de -0.7 estaban moi correlacionadas e polo tanto ofrecían información redundante. Por iso, elimináronse de análises posteriores.

As variables menos correlacionadas analizáronse mediante unha regresión loxística para determinar cales delas influían na probabilidade de que unha parcela perdese o uso agrícola no período de tempo estudado.

Antes de facer as análises de regresión loxística, cómpre que as variables teñan todas unha distribución normal. Para iso aplícase un test de Xapiro-Wilk e aquelas variables que teñen unha distribución desviada á esquerda ou á dereita corríxense mediante funcións logarítmicas. Unha vez corrixida a distribución procédese a estandarizar as variables restándolle a cada valor a media e dividindo o resultado pola desviación típica.

Unha vez transformadas as variables procédese a facer unha regresión loxística para ver cáles delas poden influír á hora de determinar a probabilidade de cambio. Para iso utilizanse os p-valores, eliminándose aquelas variables que teñen un $\mathrm{p}$-valor moi alto.

Coas variables restantes farase unha segunda regresión loxística que servirá para analizar qué peso teñen na probabilidade de que unha cela cambie de non agrícola a agrícola.

Obtención de mapa de probabilidade de urbanización de terreos de alta aptitude agrícola

Como se mencionou na introdución, o mapa de probabilidade de urbanización de terreos de alta aptitude agrícola obterase multiplicando un mapa ráster de aptitude agrícola por un mapa ráster de probabilidades de urbanización do solo.

O mapa de probabilidades de urbanización do solo xerarase mediante un modelo de autómata celular de cambios de usos do solo calibrado cos mapas dos anos 1997 e 2009. Co modelo calibrado faranse 100 simulacións para o ano 2021 (unha proxección dun período de tempo equivalente ao usado na calibración: 1997-2009). Os 100 mapas resultantes sumaranse e dividiranse entre 100 para obter a probabilidade de cambio.

O modelo a empregar é o desenvolto por García et al. (2010) que está inspirando no modelo de White et al (1997).

Este modelo considera usos activos e usos fixos. Os usos activos son aqueles que son simulados e os usos fixos son aqueles que, aínda que non participan nas dinámicas do modelo, inflúen nas dinámicas dos usos activos.

O modelo evoluciona en varias iteracións que equivalen a un ano. En cada iteración do modelo calcúlase unha probabilidade de transición para cada uso activo e cela do mapa a simular. Coñecido este potencial, cambiarán de uso as celas que teñan o potencial máis alto nun número igual á taxa anual de crecemento estimada para o uso simulado. Esta taxa calcúlase dividindo o número de celas do mapa que cambiaron ao uso simulado no período de calibrado 
(1997-2009) entre o número de anos do período.

O potencial de transición do modelo calcúlase mediante a seguinte ecuación (ecuación 2):

\section{Ec. 2: $P_{h j}=R \times v \times s_{j}^{\beta} \times\left(1+N_{j}\right)$}

Onde $P_{h j}$ é o potencial de transición do modelo para cada uso activo $j, R_{j}$ é a resistencia ao cambio dunha determinada cela ao uso $j, v$ é unha variable aleatoria (ecuación 3), sj é a aptitude do solo para albergar o uso $j, \beta$ é un coeficiente que escala o peso da aptitude no potencial de transición e $N_{j}$ determina a influencia dos usos presentes na veciñanza de cada cela do mapa no potencial de transición de ditas celas (ecuación 4)

$$
\text { Ec. 3: } v=1+[-\ln (\text { rand })]^{\alpha}
$$

Onde: rand é un número aleatorio entre 0 e 1 e $\alpha$ é un coeficiente que controla o grao de aleatoriedade introducido no modelo.

$$
\text { Ec. 3: } N_{j}=\sum_{k i d} m_{k d} i_{i d}
$$

Onde $m_{k d}$ é un coeficiente que ten en conta a influencia do uso $k$ á distancia $d$ no potencial de transición da cela ao uso $j$ e $l_{i d}$ é un coeficiente que toma valores 1 ou 0 dependendo de se a cela $i$ á distancia $d$ ten o uso $k$ ou non.

No noso caso, os usos fixos considerados no modelo foron o agrícola, forestal, ermo, excluído e vías. No caso dos usos activos, só se tivo en conta un uso urbano que agrupa os usos residencial de baixa densidade, residencial de alta densidade, industrial, comercial, institucional e parques.

No caso dos usos excluído, vías de comunicación e masas de auga asignóuselle un valor á variable $R_{j}$ moi alto para evitar que cambiasen a uso urbano. O resto de usos fixos poden cambiar a uso urbano se o potencial de transición é alto.

Para calcular o $N_{j}$ considerouse unha veciñanza circular de 3 celas de radio arredor de cada cela do mapa.

Para calibrar o modelo primeiro determinouse a aptitude para o uso urbano $\left(s_{j}\right)$ mediante regresións loxísticas, seguindo o método exposto anteriormente para analizar a influencia das variables consideradas na probabilidade de cambio a uso agrícola. $O$ resto de coeficientes do modelo $\left(\beta, \alpha, m_{k d}\right)$ calibráronse mediante un algoritmo xenético (García et al. 2010).

O mapa de aptitude do solo para o uso agrícola xerouse mediante unha suma lineal ponderada tendo en conta as variables empregadas no traballo de Corbelle (2009) e as variables dispoñibles que poderían determinar a aptitude do solo agrícola.

As variables utilizadas e os coeficientes empregados para ponderalas son os seguintes:

Altitude: 0,15

Área das parcelas: 0,05

Capacidade produtiva do solo: 0,3

Distancia aos usos agrícolas: 0,05
Distancia a camiños: 0,05

Distancia a explotacións agropecuarias: 0,05

Índice de forma das parcelas: 0,05

Orientación do terreo: 0,05

Pendente: 0,25

Aquelas variables como distancia a explotacións, onde canto menor é o valor maior ten que ser a aptitude, normalizáronse entre 0 e 1 outorgándoselle o valor 1 ao valor mínimo e 0 ao máximo. No caso da variable orientación do terreo, outorgáronse valores de 1 ás orientacións $\mathrm{SO}$ e SE, 0,8 ás orientacións $\mathrm{S}, \mathrm{E}$ e O, 0,6 ás orientacións NO e NE e 0,4 á orientación N. As pendentes de máis dun $20 \%$ asignóuselles un valor 0 por non seren aptas para a agricultura. $O$ resto de valores de pendente normalizáronse entre 0 e 1 dándolle o valor 1 á pendente máis baixa e 0 á máis alta.

\section{Resultados}

Resultados de comparar os mapas de usos dos anos 1997 e 2009

Na matriz de confusión resultante de cruzar os mapas de usos de 1997 e 2009 (táboa 1) observamos que os usos urbanos son os que máis gañan superficie cun $1,58 \%$ do total da área de estudo, seguido dos terreos forestais cun $0,3 \%$, das vías de comunicación cun $0,22 \%$ e dos terreos sen vexetación cun $0,17 \%$.

Os usos que perden superficie son o uso agrícola que perdeu un $1,35 \%$ da superficie total da área de estudo e o mato cun $0,96 \%$.

O uso agrícola perde superficie a favor do uso forestal cun $34,44 \%$ da superficie total perdida, mato cun $21,98 \%$ da superficie total perdida, residencial de baixa densidade cun $14,2 \%$ da superficie total perdida, terreos sen vexetación cun $13,42 \%$ da superficie total perdida e, en menor medida, vías e usos industriais cun $3,89 \%$ respectivamente da superficie total perdida.

Os terreos sen vexetación son un paso intermedio a usos urbanos, xa que o $73,91 \%$ dos terreos sen vexetación que cambiaron de uso fixérono a un uso urbano. Só un $14,91 \%$ dos terreos sen vexetación que cambiaron de uso fixérono a usos agrícolas. Observando os mapas, apréciase que se trata de zonas que quedaron sen construír e se revexetaron outra vez. Por todo isto cabe dicir que unha boa parte do uso agrícola pérdese en favor do uso urbano, aínda que a maioría das terras agrícolas se reforestan ou abandonan e evolucionan a matogueiras. Este último proceso é significativo do abandono da actividade agrícola na área de estudo (Marey Pérez et al. 2006) .

Por outra banda, un $1,22 \%$ do total da área de estudo pasou a ter un uso agrícola no período de tempo considerado. Os usos que cambiaron a agrícola foron na súa maioría o mato ( $56,3 \%$ da superficie que cambiou a agrícola) e o forestal ( $31 \%$ da superficie que cambiou a agrícola). Os terreos que se roturan son os de peor calidade xa que na súa maioría 
estaban a mato. De feito é unha dinámica lóxica, pois a actividade agrícola ten que competir cos usos urbanos polos terreos de mellor calidade (Corbelle e Crecente 2014).

\section{Resultados das regresións loxísticas}

Tras as análises de correlación das variables empregadas para analizar as dinámicas de cambio anteriormente descritas, obsérvase que a variable distancia ao centro da cidade está moi correlacionada con distancia a uso institucional, distancia a rúas, distancia a parques e distancia a uso residencial de alta densidade. Isto débese a

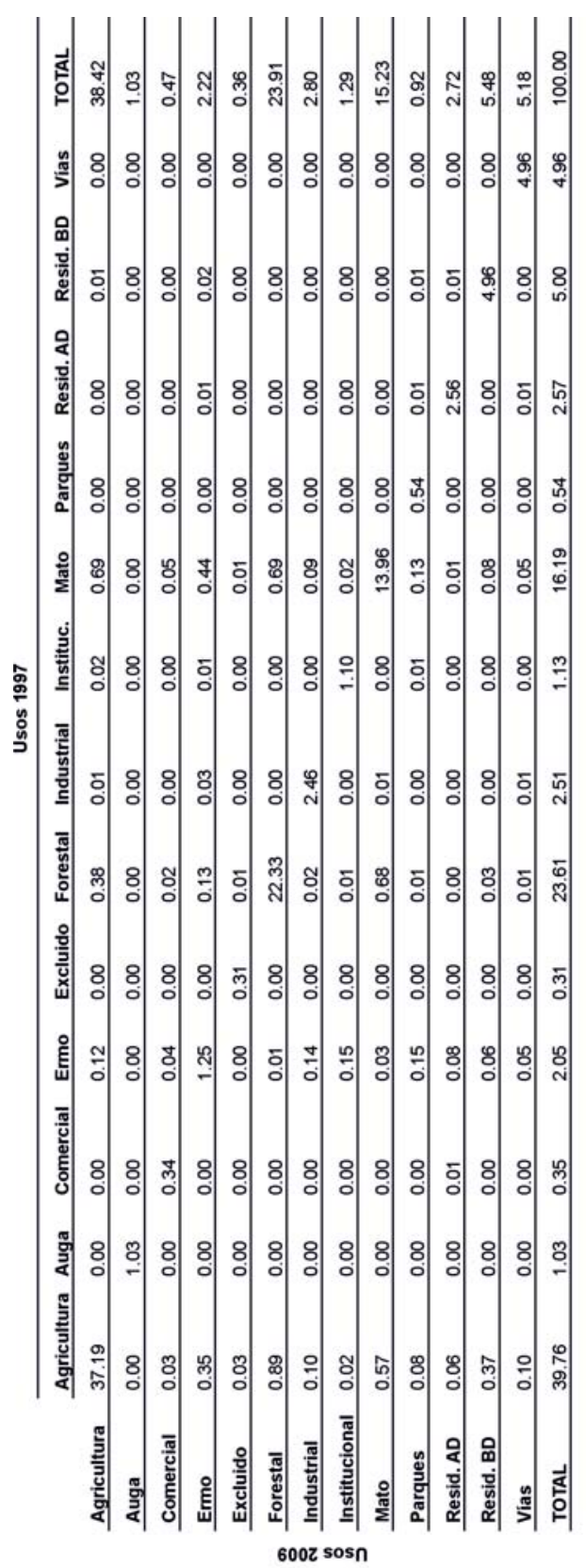

Táboa 1.- Matriz de confusión resultante de cruzar os mapas de usos de 1997 e 2009. Os datos expostos están expresados en porcentaxes sobre o total da superficie dos mapas que todos estes usos e equipamentos se concentran no centro de Lugo, e polo tanto, ao aumentar a distancia ao centro da cidade tamén aumenta a distancia a estes elementos. Por este motivo decidiuse considerar só a distancia ao centro de Lugo en análises posteriores. Doutra banda, as variables distancia a autoestradas, distancia a nodos de comunicación e distancia á vía do tren tamén están moi correlacionadas debido a que estas infraestruturas discorren case paralelas. Polo tanto, só se consideran en análises posteriores a distancia a autoestradas.

A primeira regresión loxística feita para analizar os cambios a usos agrícolas no período 1997-2003 amosa que tódalas variables teñen un $p$-valor| inferior a 0,01 . Ao observarse que a probabilidade de que as variables non inflúan na probabilidade de cambio é alta, colléronse as dúas que teñen un $p$-valor máis baixo. Estas foron distancia a usos agrícolas $(P R>|z|=0,03)$ e distancia a uso residencial de baixa densidade $(P R>|z|=0,05)$. Na regresión feita para o período 2003-2009 só a distancia a residencial de baixa densidade tivo $p$-valores inferiores de 0,01. Para non facer a segunda regresión loxística só con esta variable, tamén se colleron o resto de variables con valores baixos: distancia ao centro da cidade $(P R>|z|=0,01)$, distancia a usos forestais $(P R>|z|=0,01)$, distancia a usos industriais $(P R>|z|=0,09)$ e distancia a usos agrícolas $(P R>|z|=0,03)$.

Os resultados da segunda regresión loxística amosan os seguintes datos: para o período 1997-2003 (táboa 2), as parcelas con maior probabilidade de cambiar a uso agrícola foron aquelas que se atopaban cerca dos usos residenciais de baixa densidade. A variable de distancia a outros usos agrícolas ten un p-valor alto e polo tanto, o coeficiente obtido na regresión loxística non é fiable.

No período 2003-2006 vese que o factor que máis influencia ten é a distancia ao centro da cidade de Lugo (táboa 3); aquelas parcelas que están máis distantes son as que maior probabilidade teñen de seren transformadas. A segunda variable que ten maior incidencia é a proximidade a usos residenciais de baixa densidade. Os resultados para o resto de variables non son moi fiables debido a que os p-valores son bastante altos. Aínda así, obsérvase que inflúe a proximidade a usos forestais, a proximidade a outros usos agrícolas e as distancia a usos industriais. A proximidade a usos forestais ten sentido, pois observouse nos resultados das matrices de confusión que moitas das parcelas que se transformaban a usos agrícolas tiñan un uso forestal previo.

Cabe destacar que non se observa ningún tipo de correlación coa variable de capacidade produtiva do solo para o uso agrícola. Isto confirma que os terreos que se roturan non teñen por que ser os de maior aptitude agrícola. Pois a actividade agrícola ten que competir cos usos urbanos polo terreos de maior aptitude e vese desprazada (Corbelle Rico e Crecente Maseda, 2014). As diferenzas entre un período e outro débense a un cambio na dinámica de crecemento no segundo período, volvéndose máis expansiva debido ao aumento do crecemento urbano do final da burbulla inmobiliaria. En ciclos de alto crecemento urbano créanse patróns máis dispersos.(Dietzel et al. 2005). 


\begin{tabular}{llll}
\hline \multicolumn{4}{l}{ Parcelas que cambiaron a uso agrícola entre 1997 y 2003} \\
\hline Variables incependentes & Coeficientes & $\operatorname{Pr}(>|z|)$ & \\
\hline (Intercept) & $-3,32$ & $5,06 \mathrm{E}-18$ & $* \star$ \\
\hline Distancia a usos agricolas & 0,45 & 0,1 & \\
\hline Distancia a residencial de baixa densidade & $-1,17$ & 0,004 & $* \star$ \\
\hline
\end{tabular}

Táboa 2.- Resultados da segunda regresión loxística na que se analiza como inflúen as variables esplicativas na probabilidade de que unha cela cambie a uso agrícola no periodo 1997-2003

\begin{tabular}{llll}
\hline \multicolumn{4}{l}{ Parcelas que cambiaron a uso agricola entre 2003 e 2009 } \\
\hline Variables independentes & Coeficientes & $\operatorname{Pr}(>|z|)$ & \\
\hline (Intercept) & $-3,66$ & $1,73 \mathrm{E}-06$ & $* * *$ \\
\hline Distancia a usos agricolas & $-0,87$ & 0,03 & $*$ \\
\hline Distancia ao centro da cidade & 2,01 & 0,0006 & $* *$ \\
\hline Distancia a usos forestais & -1 & 0,03 & $*$ \\
\hline Distancia a usos industriais & 0,79 & 0,1 & \\
\hline Distancia a residencial de baixa densidade & $-1,74$ & 0,001 & $* *$ \\
\hline
\end{tabular}

Táboa 3.- Resultados da segunda regresión loxística na que se analiza como inflúen as variables esplicativas na probabilidade de que unha cela cambie a uso agrícola no periodo 2003-2009

Obtención do mapa de zonas de alta aptitude agrícola con maior probabilidade de seren urbanizadas

A bondade da calibración do modelo determinouse cruzando o mapa simulado para o ano 2009 co mapa real do mesmo ano, obtendo un índice kappa de 0.82 .

Para realizar as simulacións coas que se obtivo o mapa de probabilidade de urbanización, primeiro tívose que facer un mapa de aptitude para o uso urbano utilizando regresións loxísticas. Os resultados da segunda regresión loxística (táboa 4) amosan que os factores que máis influíron na probabilidade de que unha cela cambiase a uso urbano no período 1997-2009 foron a proximidade a usos industriais e en menor medida a proximidade a usos forestais, ao centro da cidade, ás masas de auga e á autovía. Isto indica que as parcelas que se transformaron a urbanas neste período fixérono principalmente en terreos forestais preto das zonas industriais e do centro de Lugo. Asemade, a proximidade ao río e á autovía tamén teñen influencia, pois Lugo sitúase entre estes dous elementos lineais e ao expandirse aproxímase cada vez máis a eles. Os resultados indican que a cidade estivo a medrar a conta dos terreos vacantes que se atopan entre as zonas construídas próximas ao centro.

No mapa de probabilidade de urbanización resultante de facer as simulacións para o ano 2021 (figura 2), obsérvase que as zonas con maior probabilidade de urbanización se atopan no nordeste da cidade, próximas á autovía. Estas áreas están ocupadas por varios polígonos industriais (O Ceao, As Gándaras e estrada de Vegadeo) nos que se instalaron moitas empresas nos anos do período de estudo. Tamén se construíu o novo hospital de Lugo próximo á estrada de Vegadeo. Este novo equipamento atraerá moito crecemento a esta zona nos vindeiros anos.

\begin{tabular}{llll}
\hline \multicolumn{4}{l}{ Celas que cambiaron de uso a urbano no período 1997-2009 } \\
\hline Variables independentes & Coeficientes & PR $>|\mathbf{z}|$ & \\
\hline (intercept) & $-0,0001$ & $5,43 \mathrm{E}-24$ & ${ }^{* * *}$ \\
\hline Área & 0,000002 & 0,001 & ${ }^{* *}$ \\
\hline Distancia a masas de auga & $-0,0001$ & 0,001 & ${ }^{* *}$ \\
\hline Distancia a usos forestais & $-0,0004$ & $6,05 \mathrm{E}-05$ & ${ }^{* * *}$ \\
\hline Distancia a usos industriais & $-0,002$ & $1,64 \mathrm{E}-05$ & ${ }^{* * *}$ \\
\hline Distancia ao centro da cidade & $-0,0004$ & 0,01 & ${ }^{*}$ \\
\hline Distancia á autovía & $-0,0001$ & 0,01 & ${ }^{*}$ \\
\hline
\end{tabular}

Táboa 4.- Resultados da segunda regresión loxística utilizada para xerar os mapas de aptitude para o uso urbano que se utilizarán no modelo

O Mapa de aptitude do solo para usos agrícolas (figura 3), amósanos que as zonas de maior aptitude están ao nordeste da cidade. Xusto onde se ten producido moito crecemento nos últimos anos debido á proximidade da autovía, e os polígonos do Ceao e as Gándaras. Por outro lado, tamén hai zonas de alta aptitude no suroeste, espalladas ao longo do río e da estrada de Santiago. Nesta área é onde máis crecemento disperso de usos residenciais de baixa densidade se ten producido.

Multiplicando o mapa de probabilidade de urbanización e o de aptitude obtemos o mapa que nos indica o potencial de urbanización das mellores terras agrícolas (figura 4). Este mapa axuda a identificar puntos quentes como as parcelas 
que se atopan ao norte do polígono das gándaras (próximas á autovía) e próximas ao polígono do Ceao e a estrada da Coruña. Tamén hai moitas zonas de alto potencial ao
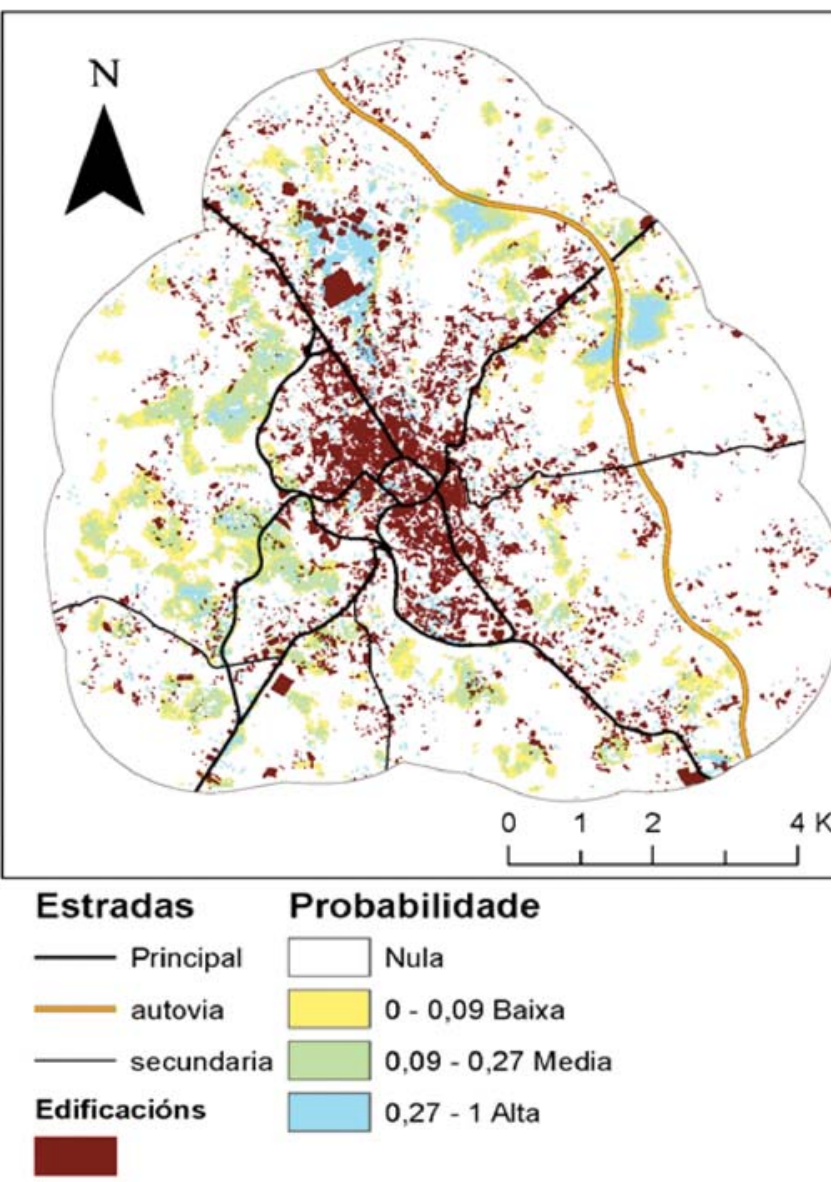

Figura 2.- Mapa de probabilidade de urbanización resultante de facer 100 simulacións cun modelo de autómata celular de cambios de usos do solo para o ano 2021

\section{Conclusións}

Os resultados das primeiras análises indican que os terreos agrícolas se están a abandonar e transformar en usos forestais. A aptitude do solo non inflúe na probabilidade de que un terreo se transforme a agrícola debido a que este uso ten que competir co uso urbano polas mellores parcelas. Isto corrobórase vendo que os resultados das regresións loxísticas indican que as parcelas que se transforman a agrícola adoitan atoparse lonxe do centro de Lugo. Malia que a maior parte dos terreos agrícolas que se urbanizan pasan a ser usos residenciais de baixa densidade, o resultado de cruzar os mapas de aptitude cos de probabilidade de urbanización amosan que o problema máis grave é debido aos usos industriais. Isto débese a que estes usos experimentaron un gran crecemento nos anos do período de estudo e a que os polígonos industriais máis grandes da cidade se atopan nunha zona de alta aptitude agrícola. Tamén se corrobora, a través do mapa de suroeste, onde se ten producido o maior crecemento disperso.

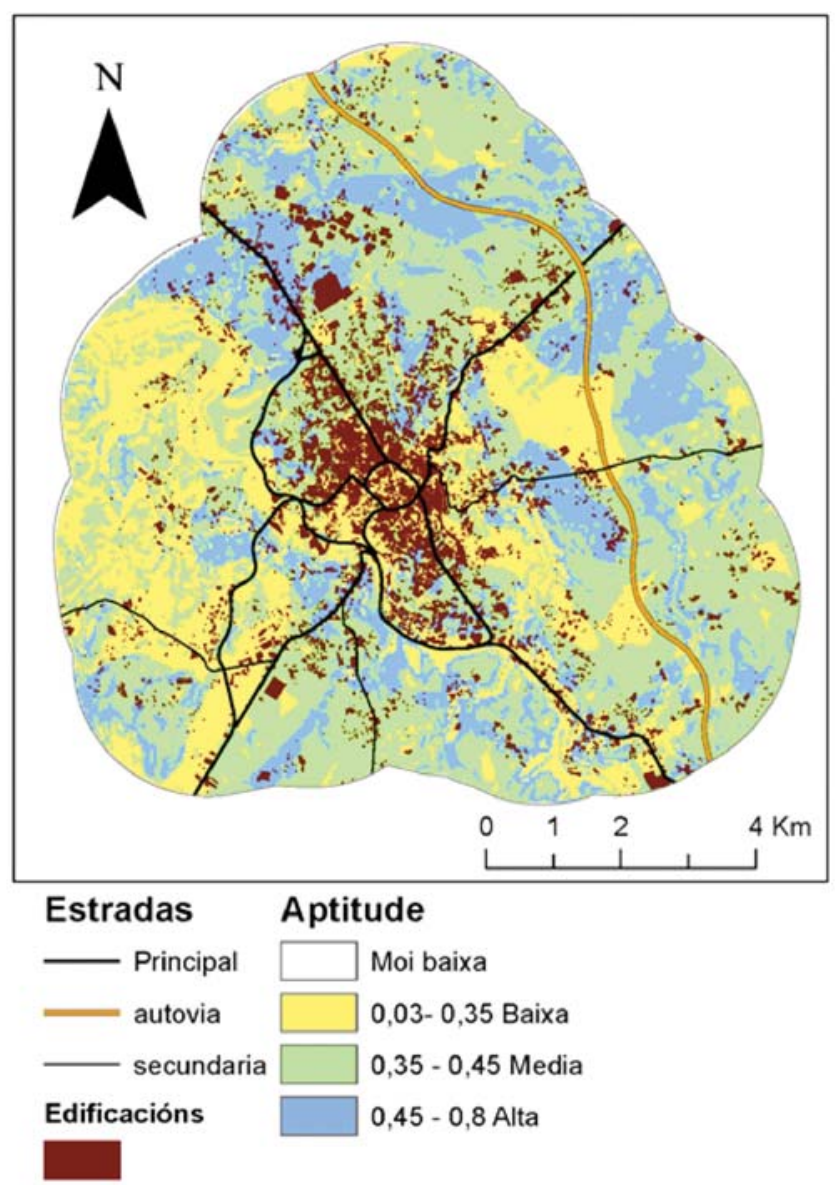

Figura 3.- Mapa de zonas con maior aptitude agrícola

potencial de urbanización de parcelas de alta aptitude agrícola, que os usos residenciais de baixa densidade están a ocupar zonas de alta aptitude no suroeste de Lugo. Non obstante, existen dous motivos polos que o potencial nestas zonas non é tan marcado como no caso do nordeste da cidade: por un lado as zonas de alta aptitude agrícola están máis espalladas e por outro os usos residenciais de baixa densidade medran de xeito disperso; polo tanto as probabilidades de urbanización non se concentran en puntos de probabilidade alta, senón que se distribúen en manchas amplas de probabilidade baixa.

A metodoloxía empregada axudou a identificar as zonas de maior prioridade á hora de tomar medidas para preservar os terreos agrícolas de maior aptitude. Deste xeito poderanse adoptar instrumentos de planeamento máis axeitados e eficaces para preservar os usos agrícolas en cada zona identificada. 

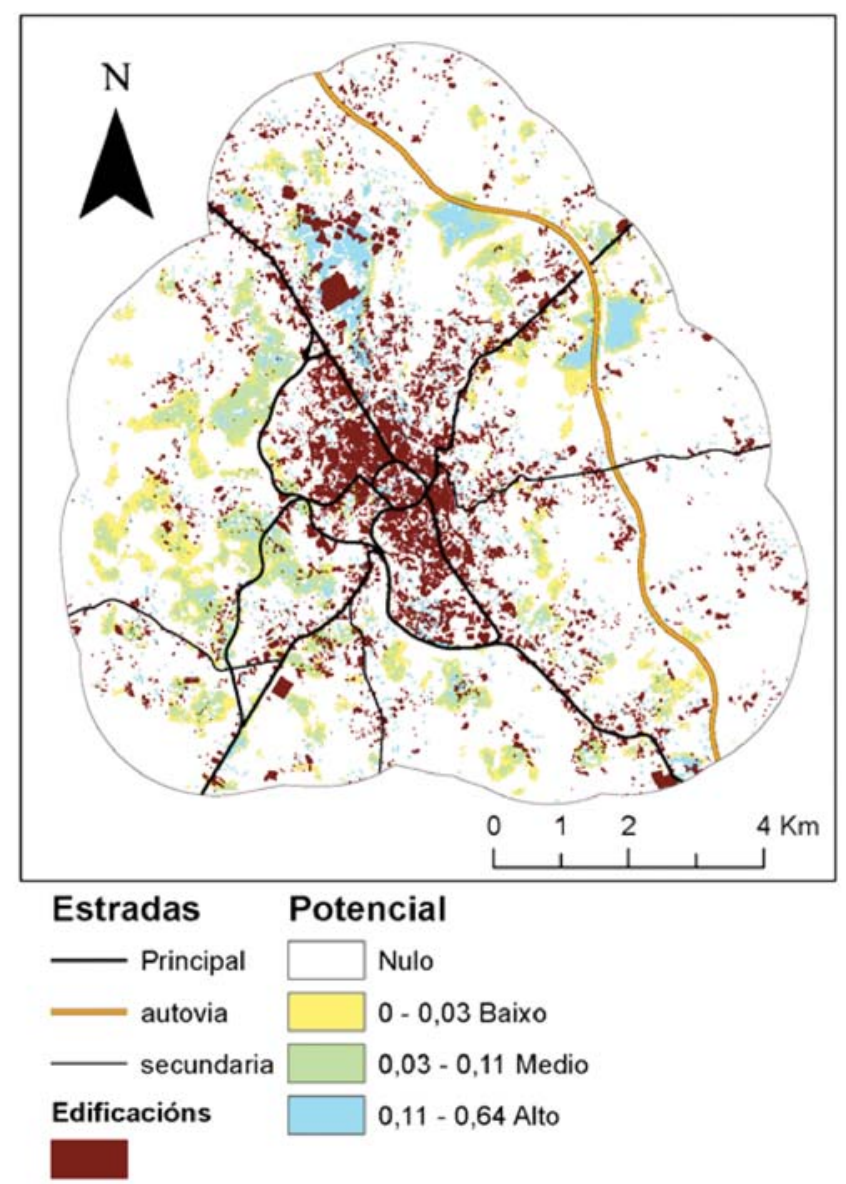

Figura 4.- Mapa de zonas de alta aptitude agrícola con maior potencial de seren urbanizadas

\section{Bibliografía}

Alonso Logroño M.P., Lois González R.C. (1997) Proceso de Industrialización y Organización Del Espacio En Un Territorio Periférico: Galicia. Boletín de La Asociación de Geógrafos Españoles, 24, 147-68.

Cabana Iglesias, A. (2008) Lo que queda de las agras: La evolución del paisaje agrario en Galicia. El caso de la comarca lucense de Terra Chá. En: XII Congreso de historia agraria, Córdoba 13-15 de marzo de 2008.

Carreira Pérez, X.C., Carral Vilariño, E. (2014) O pequeno é grande : a agricultura familiar como alternativa : o caso galego. A través, Ourense.

Corbelle Rico, E., Crecente Maseda, R. (2014) Urbanización, forestación e abandono. Cambos recentes na paisaxe de Galicia, 1985-2005. Revista Galega de economía, 23(1) , 35-52

Corbelle Rico, E., Santé Riveira, I. (2010) Caracterización dos cambios na superficie agrícola mediante técnicas de regresión: comarca de Terra Chá, 1956-2014. Recursos Rurais, 6, 23-33.
Díaz Fierros, F. E Gil, F. (1984) Capacidad productiva de los suelos de Galicia. Universidade de Santiago de Compostela.

Dietzel, C., Herold, M., Hemphill, J. J., Clarke, K. C. (2005) Spatio-temporal Dynamics in California's Central Valley: Empirical Links to Urban Theory. International Journal of Geographical Information Science 19, 175-95.

Farr, D. (2008) Sustainable urbanism; urban design with nature. John Wiley \& Sons, Hoboken (New Yersey), E.E.U.U.

Ferrás, C. (2011). De la aldea al suburbio. Cambios demográficos y territoriales en Galicia,1990-... Revista galega de economía: Publicación Interdisciplinar da Facultade de Ciencias Económicas e Empresariais, 20(extra 2), 11-30.

Ferrás, C. (1998). O modelo de desenvolvemento territorial de galicia. Eixo atlántico ou cidade xardín? En: Congreso de economía de Galicia, 13-29. Universidade de Santiago de Compostela.

García, A. M., Santé, I., Boullón, M., Crecente, R. (2013) Calibration of an urban cellular automaton model by using statistical techniques and a genetic algorithm. Application to a small urban settlement of NW Spain. International Journal of Geographical Information Science, 27(8), 15931611.

Jenerette G. D.; Wu J.G. (2001) Analysis and simulation of land-use change in the central Arizona-Phoenix region, USA. Landscape Ecology, 16(7), 611-626.

Li X.; Yeh A.G.O. (2000) Modelling sustainable urban development by the integration of constrained cellular automata and GIS. International Journal of Geographical Information Science, 14(2), 131-152.

Li X.; Yeh A.G.O. (2001) Zoning land for agricultural protection by the integration of remote sensing, GIS, and cellular automata. Photogrammetric Engineering and Remote Sensing, 67(4), 471-477.

López Iglesias, E. (2000) O sector agrario galego ás portas do século $\mathrm{XXI}$ : balance das súas transformacións recentes. Revista Galega de Economía, 9 (1), 167-196.

Marey Pérez, M.F. ; Rodríguez Vicente, V. ; Crecente Maseda, R. (2006) Using GIS to measure changes in the temporal and spatial dynamics of forestland: experiences from north-west Spain. Forestry, 79(4), 409-422

Otero, R.; Gómez, S. (2007). La desconcentración urbana en el sistema territorial de Galicia:un enfoque conceptual y empírico. Boletín de la Asociación de Geógrafos Españoles, 1(44), 259-277.

Pinto-Correia, T.; Breman, B. (2008). Understanding marginalisation in the periphery of Europe: a multidimensional process. En: Sustainable land management: strategies to cope with the marginalisation of agricultura. Roor Brouwer, Teunis van Rheenen, Shivcham S. DhiHion and Anna Martha Elgersma. Cheltenham. 1140. 
Pollan, M. (2008). The food issue - An open letter to the next farmer in chief. The New York Times [en línea]. Disponible e

http://www.nytimes.com/2008/10/12/magazine/12policyt.ht $\mathrm{ml}$ ?pagewanted=all\&_r$=0$

Precedo, A.; Míguez, A.; Fernández, M.I. (2008). Galicia: el tránsito hacia una sociedad urbana en el contexto de la unión europea. Revista galega de economía: Publicación Interdisciplinar da Facultade de Ciencias Económicas e Empresariais. 17(extra 3), 89-108.

Steel, C. (2008). Hungry City: How food shapes our lives. Vintage, Londres.
UN-HABITAT (2010). State of the World's Cities 2010/2011 - Cities for All: Bridging the Urban Divide. United Nations Human Settlements Programme (UNHabitat), Nairobi.

White, R.; Engelen, G.; Uljee, I. (1997). The use of constrained cellular automata for high resolution modelling of urban land-use dynamics. Environment and Planning B- 